\title{
Effects of Perinatal HIV Infection and Early Institutional Rearing on Physical and Cognitive Development of Children in Ukraine
}

\author{
Natasha A. Dobrova-Krol, Marinus H. van IJzendoorn, \\ Marian J. Bakermans-Kranenburg, and Femmie Juffer \\ Centre for Child and Family Studies, Leiden University
}

\begin{abstract}
To study the effects of perinatal HIV-1 infection and early institutional rearing on the physical and cognitive development of children, 64 Ukrainian uninfected and HIV-infected institutionalized and family-reared children were examined (mean age $=50.9$ months). Both HIV infection and institutional care were related to delays in physical and cognitive development, with a larger effect of the rearing environment. Family care, even of compromised quality, was found to be more favorable for children's physical and cognitive development than institutional care. The impact of the quality of child care on physical and cognitive development is discussed in light of future interventions.
\end{abstract}

Early exposure to cumulative adversity may cause enduring neurobiological changes responsible for a range of developmental deficits in different domains (Nelson, 2007). The major sources of childhood adversity are poor health, economic hardship, and compromised rearing environment. The presence of perinatal HIV infection is associated with all three of them: HIV, as a medical condition, has a direct impact on physical and cognitive development of the child; as a psychosocial phenomenon, pediatric HIV infection is usually accompanied by perinatal adversities, poverty, parental substance abuse and illness, and increased risk of child neglect, maltreatment and abandonment (Klunklin \& Harrigan, 2002; Steele, Nelson, \& Cole, 2007).

Currently, thanks to the advances in treatment, HIV infection has turned into a chronic, subacute condition rather than an acute lethal disease (e.g., De Martino et al., 2000). At the same time, due to parental death or child abandonment, HIV infection has also become a growing reason for child institutionalization (United Nations International Children's Emergency Fund, 2007). As has been repeatedly demonstrated in previous research, institutional care jeopardizes children's

This research was supported by research grants to the second and third authors from the Netherlands Organization for Scientific Research (NWO SPINOZA Prize; NWO VIDI Grant 452-04306). F.J. is supported by Wereldkinderen.

Correspondence concerning this article should be addressed to Marinus H. van IJzendoorn, Centre for Child and Family Studies, Leiden University, PO Box 9555, NL-2300RB Leiden, Netherlands. Electronic mail may be sent to vanijzen@fsw. leidenuniv.nl. optimal development (e.g., Johnson, Browne, \& Hamilton-Giachritsis, 2006). Nevertheless, several studies suggest that in some cases of extremely adverse rearing circumstances well-functioning child-care institutions may offer children a better rearing environment than their own dysfunctional families (e.g., Miller et al., 2007). Therefore, the purpose of this study was to examine the separate and combined influences of HIV status and the type of the rearing environment, that is, biological families and child-care institutions, on children's stress regulation, and physical and cognitive development, as reflected by their diurnal cortisol production, linear growth, general intelligence, and social-cognitive intelligence as indicated by theory of mind.

Previous research demonstrates that HIV infection is usually accompanied by lower birth weight and physical growth delays, and may cause inhibition of cortisol production. The growth failure of HIV-infected children is usually caused by HIV replication, with the resulting immune response affecting the metabolism and consequently physical growth. Growth delays can also occur as a result of perinatal and postnatal insults, unrelated to HIV infection, such as prenatal substance exposure, prematurity, and malnutrition prevalent among children born to HIV-infected mothers, and due to the impact of other HIV clinical symptoms, concurrent diseases, and/or treatment toxicity (Bailey,

(C) 2010, Copyright the Author(s)

Journal Compilation (C) 2010, Society for Research in Child Development, Inc. All rights reserved. 0009-3920/2010/8101-0016 
Kamenga, Nsuami, Nieburg, \& St Louis, 1999; European Collaborative Study, 2003). Furthermore, HIV may cause inhibition of the hypothalamicpituitary-adrenal system functioning due to the direct effect of the virus on adrenal gland, or as a result of concurrent diseases and/or medical treatment (e.g., Marik, Kiminyo, \& Zaloga, 2002).

Cognitive deficits in HIV-infected children can be attributed to structural central nervous system abnormalities and progressive encephalopathy caused by HIV, health condition, and stage of the disease progress (see Wachsler-Felder \& Golden, 2002, for a review). Developmental delays in HIVinfected children can, however, also be caused by adverse rearing environment (Brown, Lourie, \& Pao, 2000). In fact, several studies suggest that adverse rearing environment may have equal or even larger effects on the development of children than the infection itself (Coscia, Christensen, Henry, Wallston, \& Radcliffe, 2001; Smith et al., 2006).

An average family provides children with what is referred to as the average expectable environment. Depending on the child's age, it encompasses a range of species-specific elements, such as protective, stable caregiving, and socialization, and opens opportunities for exploration of the world (Bowlby, 1998; Cicchetti \& Valentino, 2006; Hartmann, 1958). The provision of the average expectable environment is an important prerequisite for children's normal development. For children reared in HIVimpacted families, poverty, parental substance abuse, and serious illness are compromising factors falling outside the range of the average rearing environment and leading to adverse developmental outcomes (e.g., Blanchette, Smith, King, FernandesPenney, \& Read, 2002; De Bellis, 2005; Fishkin et al., 2000; Gottlieb \& Blair, 2004).

As to institutional rearing, it clearly falls outside the range of the average expectable environment due to structural neglect that is embedded in the organization and functioning of child-care institutions (van IJzendoorn, 2008): Its regimented nature, high child-to-caregiver ratio, multiple shifts, and frequent change of caregivers almost inevitably deprive children of continuous and reciprocal interactions with stable caregivers, necessary to respond to their developmental needs. Compromised family rearing environment as well as institutional care can lead to physical growth delays (Skuse, Reilly, \& Wolke, 1994; van IJzendoorn, Bakermans-Kranenburg, \& Juffer, 2007), stress dysregulation (Gunnar \& Vazquez, 2006), lower IQ (Nobel, McCandliss, \& Farah, 2007; van IJzendoorn, Luijk, \& Juffer, 2008), and delayed false belief understanding (Cicchetti,
Rogosch, Maughan, Toth, \& Bruce, 2003; Pears \& Fisher, 2005; Tarullo, Bruce, \& Gunnar, 2007; Yagmurlu, Berument, \& Celimli, 2005).

The link between compromised rearing environment and developmental deficits may operate through child-caregiver interactions. Studies suggest that even in the condition of structural institutional neglect the quality of caregiving plays a leading role in the children's development. Thus, Smyke et al. (2007) found that for institution-reared children, the caregiving quality was related to three of six developmental outcomes, including cognitive development. Based on adoptive parents' retrospective reports on the standards of institutional care, Castle et al. (1999) established that individualized care in institutions had the strongest positive effect on adoptees' IQ. Intervention studies also support the importance of child-caregiver relationships, demonstrating that even a modest increase of visual, tactile, and auditory interaction between a child and a caregiver (Hakimi-Manesh, Mojdchi, \& Tashakkori, 1984), or some extra untutored human care (Hunt, Mohandessi, Ghodssi, \& Akiyama, 1976) results in improved physical and mental development of institution-reared children (for a review and meta-analysis of interventions with institutionalized children, see Bakermans-Kranenburg, van IJzendoorn, \& Juffer, 2008).

Physical surroundings represent another aspect of the rearing environment influencing child development (directly and via caregivers; see Evans, 2006, for a review). Morison, Ames, and Chisholm (1995) showed that developmental delays in children with early institutional experience were less severe in the presence of toys and worse when children were dirty or soiled while in institutional care. Studies of family-reared children consistently demonstrated that a stimulating and well-organized physical environment allowing free exploration of developmentally adequate objects, toys and books, and language stimulation by caregivers have a positive effect on children's development (e.g., Bradley, 1985). In the current study, we explored how these factors were related to the development of HIV-infected children.

According to Gunnar's (2001) classification, the institutions involved in our study were characterized by the second level of institutional privation, providing adequate nutrition and health care, however, lacking stimulation and stability in child-caregiver relationships (Dobrova-Krol, van IJzendoorn, Bakermans-Kranenburg, Cyr, \& Juffer, 2008). This being the case, the question arose whether family care even of compromised quality, 
as in the case of HIV-impacted families, facilitates the development of HIV-infected children better than institutional care. Or will perhaps institutions that provide fairly clean environments, good medical care, and nutrition, such as those where the present study was conducted, be good enough to facilitate the development of children better than the troubled family environment that HIVimpacted parents provide? And to what extent does the presence of HIV undermine the development of the institution-reared children as compared to their noninfected institution-reared peers? To address these questions, we compared stress regulation, and physical and cognitive development of HIV-infected children with about the same level of immune control over the infection, as reflected by their CD4 T-lymphocyte count (McMichael \& Rowland-Jones, 2001), in different rearing environments: families versus institutions. To examine the effect of HIV infection on physical and cognitive development with respect to the type of the rearing environment, we also included family- and institution-reared children without the HIV condition.

We predicted the following: (a) both HIV infection and institutional rearing would lead to stress dysregulation and delayed physical and cognitive development, with an expected larger effect of the rearing environment than of HIV infection, and (b) even compromised family care was expected to be more favorable for the child's development than institutional care, but quality of care within the institution was predicted to be associated with level of cognitive development.

\section{Method}

\section{Participants}

Participants were 64 children: 13 HIV-infected institution-reared children (mean age $=52.28$ months, $S D=12.99$, range $=34.78-74.16)$, 16 uninfected institution-reared children (mean age $=$ 48.14 months, $S D=9.72$, range $=35.11-66.73)$, 16 HIV-infected family-reared children, (mean age $=$ 52.01 months, $S D=14.78$, range $=30.18-71.56)$, and 19 uninfected family-reared children (mean age $=$ 51.44 months, $S D=9.77$, range $=37.48-67.06$ ). The groups did not differ with respect to age and gender. Data on the background characteristics of children are presented in Table 1. All HIV-infected children were born to seropositive mothers and acquired the infection perinatally. Diagnosis of HIV-1 infection was based on positive viral culture of polymerase chain reaction assay performed after the neonatal period on at least two occasions over 2 months. In the group of uninfected institutionreared children, 5 had perinatal hypoxic neurological conditions (PHNC), whereas there were no cases of PHNC in the three remaining groups. Because previous studies have demonstrated that PHNC are related to altered physical and cognitive development and stress regulation (Ellis et al., 2001; Van Handel, Swaab, De Vries, \& Jongmans, 2007), we decided to exclude these children from further analysis. Moreover, one of the HIV-infected family-reared children was excluded because of clear signs of fetal alcohol syndrome not reported in the medical records, resulting in an effective sample of 58 children. The power of the current

Table 1

Descriptive Statistics for Family-Reared Versus Institution-Reared Children

\begin{tabular}{|c|c|c|c|c|c|c|c|c|}
\hline & \multicolumn{4}{|c|}{ Family-reared children } & \multicolumn{4}{|c|}{ Institution-reared children } \\
\hline & \multicolumn{2}{|r|}{ HIV- } & \multicolumn{2}{|r|}{$\mathrm{HIV}+$} & \multicolumn{2}{|r|}{ HIV- } & \multicolumn{2}{|r|}{$\mathrm{HIV+}$} \\
\hline & $n^{\mathrm{a}}$ & $M(S D)$ & $n^{\mathrm{a}}$ & $M(S D)$ & $n^{\mathrm{a}}$ & $M(S D)$ & $n^{\mathrm{a}}$ & $M(S D)$ \\
\hline \multirow{6}{*}{$\begin{array}{l}\text { Age of mother (years) } \\
\text { Family income } \\
\text { Age of child (months) } \\
\text { Weight-for-age at birth } \\
\text { CD4 T-lymphocyte count }\end{array}$} & 17 & $32.12 \quad(5.93)$ & 14 & 32.47 & 11 & $30.18 \quad(8.73)$ & 8 & 30.38 \\
\hline & 12 & $234.75_{a}(112.29)$ & 13 & $149.54_{b} \quad(43.10)$ & & & & \\
\hline & 19 & $51.44 \quad(9.77)$ & 16 & $52.01 \quad(14.78)$ & 16 & $48.14 \quad(9.72)$ & 13 & $52.28 \quad(12.99)$ \\
\hline & 16 & $-0.32_{a} \quad(0.99)$ & 15 & $-1.15_{\mathrm{ab}} \quad(1.21)$ & 15 & $-0.81_{\mathrm{ab}}(0.61)$ & 13 & $-1.36_{b} \quad(0.56)$ \\
\hline & & & 14 & $913.21 \quad(459.91)$ & & & 13 & $1,147.69 \quad(375.01)$ \\
\hline & & $n(\%)$ & & $n(\%)$ & & $n(\%)$ & & $n(\%)$ \\
\hline Perinatal complications & 19 & & 16 & & 16 & $5(37.5)$ & 13 & \\
\hline Antiretroviral therapy & & & 16 & $6 \mathrm{a}(37.5)$ & & & 13 & $12_{b}(92.3)$ \\
\hline
\end{tabular}

Note. Mean values in the same row that do not share subscripts differ at $p<.05$.

${ }^{a}$ Number of cases with available data. 
design with two factors (HIV and rearing environment; $N=58$ children) and an expected large effect size $(f=.40)$ was .82 ; for the multivariate analyses including one covariate (birth weight; see the following) the power was .85 .

Institution-reared children. Institution-reared children were recruited from four Children's Homes in Ukraine. The following selection criteria were applied: (a) age between 3 and 6 years old, (b) admission to institutional care within the 1st year of life, (c) no genetic syndromes (e.g., Down syndrome), (d) no evidence of fetal alcohol syndrome in the medical records, and (e) permanent residence in residential care institutions since admission. These selection criteria substantially limited the number of children who could participate in the study. On average, the mean age at admission to institutional care of the uninfected children was 1 month $(S D=1$, range $=0-3)$, and they had been living in institutions for 47 months $(S D=9$, range $=$ 35-65). The mean age at admission to institutional care of the HIV-infected children was also 1 month $(S D=2$, range $=0-7)$. One child who was admitted at 7 months of age previously had lived in a hospital and was cared for by the hospital staff. HIVinfected children had been living in institutional care for 51 months on average $(S D=14$, range $=$ 35-74).

The data on the history of institutionalization showed that in the group of uninfected institutionreared children, 9 were admitted to institutional care because of poverty, 2 because of family disruption, 4 because one or both parents were in prison, and 1 child was an orphan. Since admission to institutional care, 7 of the uninfected children were transferred from one institution to another. For 1 child, information about the number of transfers between institutions was missing. Seven uninfected children remained in occasional contacts with their parents or family members. Among the uninfected institution-reared children, 2 had siblings living in the same institution; the siblings did not participate in our study.

In the group of HIV-infected institution-reared children, 1 child was admitted to institutional care due to poverty, 1 child due to family disruption, and 5 children because one or both parents were in prison; 6 of the HIV-infected institution-reared children were orphans. Five HIV-infected children were once transferred from one child-care institution to another. Three of the HIV-infected children remained in occasional contacts with their biological family members. HIV-infected children had no siblings residing in the same institution.
Family-reared children. Family-reared children were recruited from local Ukrainian kindergartens, schools, and clinics where routine health checks take place. Caregivers of HIV-infected family-reared children were contacted through a nongovernmental organization providing psychosocial support to HIV-infected people in the region. Some of the contacted caregivers refused to participate in the study mainly because several measures (see the following) involved the video-recording of activities at home; some parents refused to participate because of the seemingly complicated procedure of diurnal salivary cortisol sampling, which along with the strict selection criteria limited our sample size. Children were selected according to the following criteria: (a) age between 3 and 6 years old, (b) living in biological families, (c) no genetic syndromes (e.g., Down syndrome), (d) no evidence of fetal alcohol syndrome in the medical records, and (e) no previous history of institutionalization.

All uninfected children were reared in two-parent biological families with at least one employed parent. In two cases, the excessive use of alcohol by fathers was reported. There were no reported cases of criminal records among the parents of uninfected family-reared children. Among HIV-infected family-reared children, 8 were living in two-parent biological families, 4 were reared by single mothers, and 3 by their single biological grandmothers as their parents were unable to take care of the children due to drug abuse. In eight families, at least one parent was using alcohol and/or drugs and in one family both parents were abusing alcohol. In three families, both parents were unemployed. In four families, at least one parent had a criminal record and in one case both parents had criminal records. In two cases, data on criminal records of the fathers were missing. Both uninfected and HIV-infected family-reared children were raised in families with low to middle income, but the monthly income of the HIV-impacted families was significantly lower than of families without HIV, $t(23)=2.54, p<.05$. We tested whether income of the families as a proxy for family socioeconomic status (SES) impacted the outcome measures of the family-reared children, but no significant difference emerged $(.15<p<.46)$.

\section{Procedure}

For all children enrolled in the study, informed consent was obtained; for the children in the children's homes from the local department of the Ministry of Health, and for the children in the family-reared group from their parents or primary 
caregivers. All children were invited for a laboratory assessment procedure. Institution-reared children were accompanied by their "favorite" caregiver, as determined through preliminary informal interviews with children and caregivers. If a favorite caregiver was difficult to identify, the person who spent most of the time with a child and knew him or her best was invited. Family-reared children were accompanied by their primary caregiver. During the laboratory assessment procedure, the children underwent a physical examination (height, weight, and head circumference) and were administered an abbreviated, nonverbal cognitive performance test (Snijders-Oomen Nonverbal Intelligence Test-Revised [SON-R]) and a Theory of Mind (ToM) task. Because of limited time and resources, assessment of the rearing environment was possible only for the HIV-infected children and was conducted during home visits in the case of family-reared children and during visits to childcare institutions for institution-reared children.

\section{Measures}

Child HIV-1 health status. Following the assessment procedure, the children's medical records from the regional AIDS center were reviewed in order to obtain the following data: immunological status according to the Centers for Disease Control and Prevention (CDC) classification, cluster of differentiation 4 (CD4) T-lymphocyte counts that reflect the level of immune control over the infection (McMichael \& Rowland-Jones, 2001), and duration and type of antiretroviral treatment. CD4 cell counts most proximal to the time of assessment were used (range $=1-3$ months). Preliminary analysis revealed no significant difference between the HIV-infected family-reared and institution-reared children on CD4 cell counts, $t(27)=-1.48, p=.15$ (see Table 1). Out of 20 children subjected to the treatment, 18 received the same antiretroviral medications. Table 1 shows that $37.5 \%$ of family-reared children and $92.3 \%$ of institution-reared children were receiving antiretroviral therapy at the time of the assessment; no significant difference between family-reared and institution-reared children was found on duration of antiretroviral treatment $t(15)=-0.57, p=.58$. We tested whether the children receiving antiretroviral therapy differed from the nontreated HIV-infected children on all outcome measures, but no significant difference emerged $(.15<p<.94)$.

Physical growth. Data on physical growth were collected from the children's medical records. Mea- surements of current height, weight, and head circumference of all children were conducted by a trained research assistant during the laboratory visit. For the purposes of the present study, we used birth weight as a marker for prenatal adversities (e.g., Nordstrom-Klee, Delaney-Black, Covington, Ager, \& Sokol, 2002; Shankaran et al., 2004). Current height, weight, and head circumference were highly correlated ( $r s>.50$ ), and because faltering of height serves as a good indicator of long term chronic adversities (e.g., Miller, 2005), current height-for-age scores were used as index for physical growth. Height-for-age (HAZ) was calculated with the software program Epi Info ${ }^{\mathrm{TM}}$, Version 3.3.2 using the sex-specific 2000 CDC reference database (Dean et al., 2002).

Diurnal salivary cortisol sampling. A six-sample protocol was followed. Saliva samples were collected on a typical day from the institution-reared children by an institutional nurse and from the family-reared children by their parent. The standard saliva collection protocol and assay procedure for determining cortisol concentration in the saliva samples was applied (see for details, BakermansKranenburg, van IJzendoorn, Mesman, Alink, \& Juffer, 2008; Dobrova-Krol et al., 2008). Due to the low concentration of saliva within the cotton swabs, 5 HIV-infected and 5 uninfected family-reared children had missing data at one or two of the six sampling points. In these cases, missing cortisol values were generated with log curve estimation analyses using individual sampling times as the independent variable, resulting in 52 children with complete cortisol data. Three HIV-infected children and 1 uninfected family-reared child who had missing data at more than two sampling points as well as 1 HIV-infected family-reared child who refused to cooperate were not included in the analysis involving diurnal cortisol. Another uninfected familyreared child was excluded from the analyses involving diurnal cortisol because he was ill on the day of saliva sampling. Diurnal cortisol scores were $\log$ 10-transformed prior to analyses (Azar et al., 2004).

In order to assess the overall secretion of cortisol from awakening until bedtime the "area under the curve with respect to ground" (AUCg) was computed (Pruessner, Kirschbaum, Meinlschmid, \& Hellhammer, 2003). Since the AUCg was related to the total time that the children were awake (from awakening till bed time), we corrected the AUCg for children's total time of being awake. In the group of HIV-infected institution-reared children, two outliers on the AUCg were assigned a raw 
score on the offending variable that differed 1 unit from the next most extreme score in the distribution (Tabachnik \& Fidell, 2007).

Cognitive performance. The SON-R was used to assess the children's cognitive performance (Tellegen, Winkel, Wijnberg-Williams, \& Laros, 1998). The SON-R is a nonverbal intelligence test for children between 2.5 and 7 years of age that does not require the use of spoken or written language. The test consists of six nonverbal subtests that focus on two different types of abilities: visual-spatial abilities (meaningful pictures) and abstract reasoning (nonmeaningful pictures). Previous research showed that the nonverbal SON-R test is well suited for use with children of ethnic minorities in the Netherlands (Tellegen \& Laros, 1993) and in other countries (e.g., Australia: Jenkinson, Roberts, Dennehy, \& Tellegen, 1996; China: Zhang, Gong, Sun, \& Tian, 1997). In our study, we selected two of the most reliable subtests of the SON-R to assess the children's cognitive performance (Tellegen \& Laros, 1993): a visual-spatial performance Patterns subtest and an abstract reasoning Analogies subtest; average internal consistency of the subtests was .76. Convergent validity of the SON-R IQ with the Wechsler Intelligence Scale for Children-Revised Full Scale Intelligence Quotient and Performance Intelligence Quotient was .80, and with the Raven's matrices .74 (Tellegen \& Laros, 1993). In our sample, the internal consistency of the used subtests as estimated by Cronbach's alpha was .81. Total cognitive performance score was calculated with the $\mathrm{SON}-\mathrm{R}$ computer program on the basis of the two subtests.

Theory of Mind. To assess the children's ability to comprehend false belief, we used one of the False Belief tasks: the classic Unexpected-Transfer Task (Baron-Cohen, Leslie, \& Frith, 1985). The Unexpected-Transfer Task has a number of advantages when testing children without or with very little productive language skills due to its easily understood storyline supplemented by the use of props, simple vocabulary, and its nonverbal response mode (Baron-Cohen, 1992; Garfield, Peterson, \& Perry, 2001). The Unexpected-Transfer Task demonstrated good test-retest reliability, with a kappa of .62 (Hughes et al., 2000). The task was acted out with two dolls, Sally and Anne, each with a different colored basket and a ball, and involved unseen displacement of the object, in which Sally puts a ball in her basket and then leaves the scene. While Sally is away and cannot watch, Anne takes the ball out of Sally's basket and puts it into her box. Sally then returns and the children are asked where they think she will look for her ball. To pass the task children were to answer that Sally will look inside her basket before realizing that her ball is not there, and thus predict an action based on an attributed false belief. The names of the dolls were changed into the culturally appropriate ones.

Rearing environment. The Home Observation for Measurement of the Environment (HOME) inventory was employed to assess the rearing environments of HIV-infected family- and institutionreared children. The Early Childhood HOME inventory is designed to measure the quality and quantity of stimulation and support available to a child in the rearing environment (Bradley et al., 1993). The information needed to score the HOME was obtained during a 45- to 90-min visit to the place where the child lived, during a time when the child and the child's primary caregiver were present and awake. The semistructured interview and observation were conducted with minimal obtrusiveness and allowed observed participants to act normally (Caldwell \& Bradley, 2003). The Child Care Early Childhood version of the HOME (CCEC-HOME) designed for use between 3 and 6 years of age was employed in the study. It contains 58 items clustered into eight subscales: Learning Materials, Language Stimulation, Physical Environment, Caregiver Responsivity, Academic Stimulation, Modeling, Variety of Experience, and Acceptance. The inventory was translated into Russian and the interviewers were trained by the first author. In order to calculate interrater reliabilities, a second observer coded $93 \%$ of the CC-EC-HOME observations: Intraclass correlation coefficients for all the subscales scores and the total HOME scores ranged from .73 to .94 .

Background characteristics. Univariate analyses of variance (ANOVAs) and chi-square tests showed no significant differences between the four groups on age of the biological mother, child gender, or child age. Differences on the variables related to child background characteristics are presented in Table 1.

\section{Results}

\section{Preliminary Analysis}

Preliminary analyses did not reveal an association between gender and any of the outcome variables, that is, height at the assessment, diurnal cortisol production, and cognitive performance. Birth weight was significantly related to current 
height $(p<.01)$, marginally related to cognitive performance on SON-R $(p=.06)$, and not related to ToM $(p=.11)$. We used birth weight as a covariate in our analyses involving height and SON-R. Current age of the child was significantly related only to ToM $(p<.01)$ and was taken into account in analyses involving this variable. Mean values and standard deviations of height, diurnal cortisol production, cognitive performance on SON-R, and percentages of children who passed the ToM task are presented in Table 2.

\section{Differences Between Uninfected and HIV-Infected} Family- and Institution-Reared Children on Height, Stress Regulation, and Cognitive Performance

Height. Figure 1, based on the height-for-age mean values with standard errors from birth to
48 months of age, shows the development of height of the four groups across infancy and early childhood. Although both groups of HIV-infected children had lower supine length at birth than their uninfected counterparts, this difference was significant only between uninfected family-reared children and HIV-infected institution-reared children $(p<.01)$. Figure 1 shows a normal pattern of linear growth of the uninfected family-reared children remaining within $1 S D$ (range $=0.29$ to 0.87 ) of the reference population. For the other three groups, a faltering of linear growth after birth was observed at different periods of their development: the height of the HIV-infected family-reared children remained within $1 S D$ (range $=-0.97$ to 0.08 ) of the reference population, the height of the uninfected institution-reared children ranged from -2.09 to -0.75 , and the height of the HIV-infected institu-

\section{Table 2}

Mean Values and Standard Deviations for Height, Diurnal Cortisol Production, and Cognitive Performance on SON-R, as a Function of Rearing Environment and HIV Status, Controlling for Birth Weight and Percent of Children Who Passed the ToM Task

\begin{tabular}{|c|c|c|c|c|c|c|c|c|c|c|}
\hline & \multicolumn{4}{|c|}{ Family-reared children } & \multicolumn{4}{|c|}{ Institution-reared children } & \multirow[b]{3}{*}{$F$} & \multirow[b]{3}{*}{$\chi^{2}$} \\
\hline & \multicolumn{2}{|r|}{ HIV- } & \multicolumn{2}{|r|}{$\mathrm{HIV}+$} & \multicolumn{2}{|r|}{ HIV- } & \multicolumn{2}{|r|}{$\mathrm{HIV}+$} & & \\
\hline & $n$ & $M(S D)$ & $n$ & $M(S D)$ & $n$ & $M(S D)$ & $n$ & $M(S D)$ & & \\
\hline Height & 16 & $0.12_{\mathrm{a}} \quad(0.78)$ & 15 & $-0.61_{\mathrm{ab}} \quad(1.06)$ & 11 & $-0.89_{\mathrm{bc}}(0.72)$ & 13 & $-1.86_{c} \quad(1.30)$ & $7.02^{* *}$ & \\
\hline Cortisol $^{\mathrm{a}}$ & 15 & $0.45 \mathrm{a} \quad(0.18)$ & 12 & $0.47_{\mathrm{ab}} \quad(0.27)$ & 11 & $0.63_{\mathrm{b}} \quad(0.15)$ & 13 & $0.40_{a} \quad(0.17)$ & $2.80^{*}$ & \\
\hline SON-R & 16 & $98.94_{a}(19.59)$ & 15 & $79.07_{\mathrm{b}} \quad(16.90)$ & 11 & $69.73_{\mathrm{bc}}(21.28)$ & 13 & $64.00_{c}(14.32)$ & $8.59^{* *}$ & \\
\hline $\mathrm{ToM}^{\mathrm{b}}$ & 18 & $61.1_{\mathrm{a}}$ & 16 & $25.0_{\mathrm{b}}$ & 11 & $18.2_{\mathrm{b}}$ & 13 & $23.1_{b}$ & & $8.33^{*}$ \\
\hline
\end{tabular}

Note. Mean values in the same row that do not share subscripts differ at $p<.05$. Height $=$ height-for-age $Z$ score at the assessment day; SON-R = Snijders-Oomen Nonverbal Intelligence Test-Revised; ToM = Theory of Mind.

${ }^{a}$ Diurnal production of cortisol computed with AUCg (area under the curve with respect to ground) formula. ${ }^{\mathrm{b}}$ Unexpected-Transfer Task.

${ }^{*} p<.05 .{ }^{* *} p<.01$.

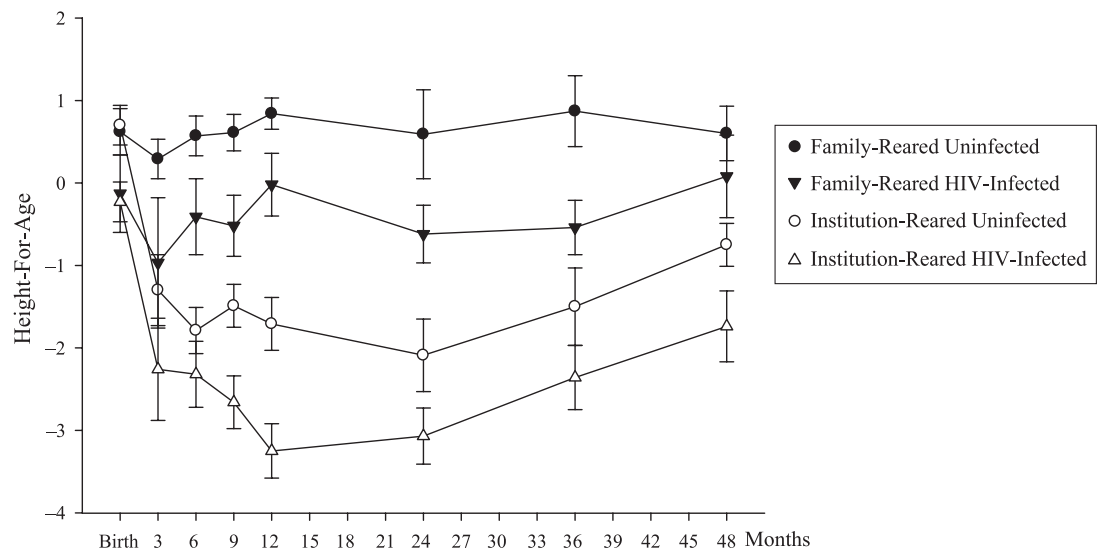

Figure 1. Height-for-age ( $Z$ scores, mean, standard error) of uninfected and HIV-infected family- and institution-reared children. Note. At 36 months, $N=47$ (family-reared uninfected $=8$, family-reared infected $=16$, institution-reared uninfected $=10$, institutionreared infected $=13$ ); at 48 months, $N=35$ (family-reared uninfected $=8$, family-reared infected $=11$, institution-reared uninfected $=7$, institution-reared infected $=9$ ). 
tion-reared children ranged from -3.25 to -1.74 . At the time of the assessment, all four groups had mean height-for-age scores within $2 S D$ from the reference population (see also Table 2).

Stress regulation: Diurnal cortisol production. Figure 2 illustrates diurnal cortisol curves of uninfected and HIV-infected family- and institution-reared children. Table 2 shows the mean values of the total diurnal cortisol production for the four groups of children.

Cognitive performance: $S O N-R$ and ToM. As Table 2 shows, cognitive performance on SON-R of the uninfected family-reared children was in the average range $(M=98.94, S D=19.59)$, performance of HIV-infected family-reared children was in the borderline deficiency range $(M=79.07, S D=16.90)$, and performance of uninfected institution-reared children $(M=69.73, S D=21.28)$ and HIV-infected children $(M=64.00, S D=8.59)$ fell in the range of mental deficiency according to the SON-R norms

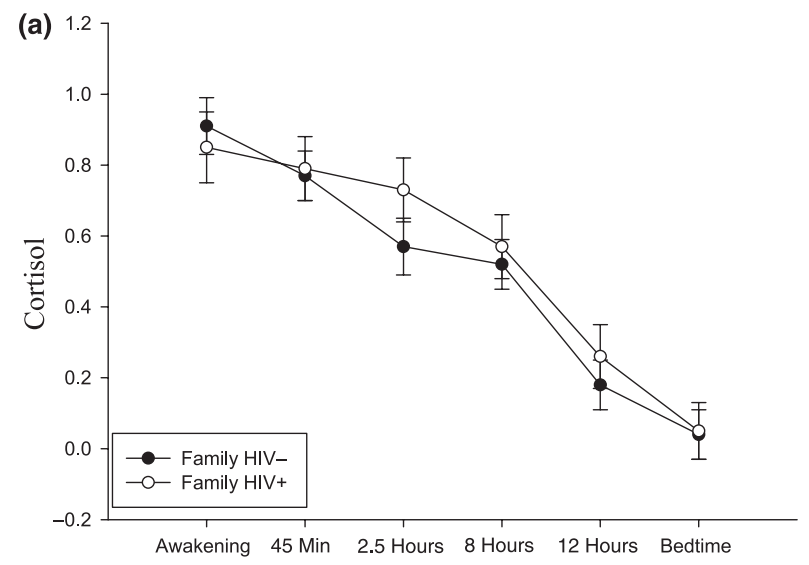

(Tellegen et al., 1998). Table 2 presents the percentages of children who passed the ToM task.

\section{Multivariate Analyses}

In Table 3, bivariate correlations between the control and outcome variables in the whole sample and as a function of the rearing environment and HIV infection are presented. To assess the difference between the groups as a function of the rearing environment and HIV status, we conducted a multivariate analysis of covariance (MANCOVA) on current height, diurnal cortisol production, and cognitive performance, controlling for birth weight. Significant overall effects were found for rearing environment, $F(3,44)=10.23, p<.01$, partial $\eta^{2}=.41$, and for HIV status, $F(3,44)=3.01, p=.04$, partial $\eta^{2}=.17$. Subsequent ANCOVAs showed main effects for rearing environment and HIV status for both height and cognitive performance and a

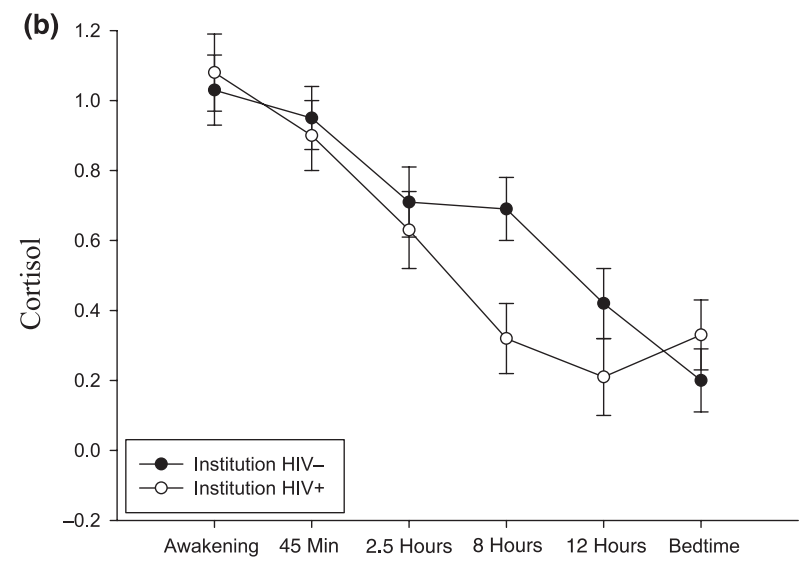

Figure 2. Diurnal cortisol values (nmol/L, log-transformed) of uninfected and HIV-infected family-reared children (a) and institutionreared children $(b)$.

Table 3

Intercorrelations for the Outcome Variables Across and Within Uninfected Versus HIV-Infected, Family-Versus Institution-Reared Groups

\begin{tabular}{|c|c|c|c|c|c|c|c|c|c|c|c|c|c|c|c|c|c|c|}
\hline & \multicolumn{6}{|c|}{ Total } & \multicolumn{6}{|c|}{ HIV-infected group } & \multicolumn{6}{|c|}{ Institution-reared group } \\
\hline & 1 & 2 & 3 & 4 & 5 & 6 & 1 & 2 & 3 & 4 & 5 & 6 & 1 & 2 & 3 & 4 & 5 & 6 \\
\hline 1.WAZ & - & & & & & & - & -.16 & .23 & -.04 & .25 & .25 & - & -.03 & .28 & .04 & .29 & .23 \\
\hline 2. Age & .03 & - & & & & & .06 & - & -.25 & .03 & -.11 & .31 & .09 & - & -.19 & .05 & .01 & $.35^{*}$ \\
\hline 3. HAZ & $.38^{* *}$ & .02 & - & & & & .29 & -.17 & - & $-.47^{*}$ & .27 & $.49^{* *}$ & $.60^{* *}$ & .15 & - & -.03 & .22 & $.40^{*}$ \\
\hline 4. Cortisol & .12 & -.15 & -.08 & - & & & .08 & .06 & .01 & - & -.28 & -.36 & .38 & -.37 & .01 & - & -.03 & .16 \\
\hline 5. SON-R & .25 & .12 & $.41^{* *}$ & .00 & - & & -.01 & .12 & $.39^{*}$ & .12 & - & .26 & .01 & .17 & .20 & .27 & - & .08 \\
\hline 6 ToM & .22 & $.36^{* *}$ & $.44^{* *}$ & -.09 & .24 & - & $.43^{*}$ & .45 & .34 & .06 & .03 & - & .09 & .32 & .37 & $-.41^{*}$ & .24 & - \\
\hline
\end{tabular}

Note. WAZ = weight-for-age $\mathrm{Z}$ score at birth; HAZ = height-for-age $\mathrm{Z}$ score at the assessment day; SON-R = Snijders-Oomen Nonverbal Intelligence Test-Revised; ToM = Theory of Mind.

${ }^{*} p<.05 .{ }^{* *} p<.01$. 
significant interaction effect for diurnal cortisol production (see Table 2). A priori contrasts revealed that uninfected family-reared children had significantly better scores on current height than both institution-reared groups, and performed significantly better on the SON-R test than all other groups. No significant difference on current height and SON-R between the HIV-infected family-reared children and uninfected institution-reared children was found. HIV-infected institution-reared children had significantly lower current height and SON-R scores than both family-reared groups, but they did not differ significantly from the uninfected institution-reared group (see Table 2). Diurnal production of cortisol was significantly higher in the group of uninfected institution-reared children as compared to uninfected family-reared children and HIVinfected institution-reared children, but uninfected institution-reared children did not differ significantly from HIV-infected family-reared children.

For ToM, chi-square analysis based on the extension of the Fisher's exact test for larger contingency tables and for small sample sizes (Verbeek \& Kroonenberg, 1985) demonstrated significant differences between the groups, $\chi^{2}(3, N=58)=8.33, p=.04$, with family-reared uninfected children outperforming the other three groups of children. To control for age, we used a median split of the sample on age and compared the children's ToM performance among younger (<47.86 months) and older (> 47.86 months) children. We found that in the group of younger children the success rate was $43 \%$ for uninfected family-reared children and 17\% for HIV-infected institution-reared children; none of the HIV-infected family-reared and uninfected institution-reared children passed the task. Among older children the success rate was $73 \%$ for uninfected family-reared children, $67 \%$ for uninfected institution-reared children, 50\% for HIV-infected family-reared children, and $29 \%$ for HIV-infected institution-reared children. Separate chi-square analysis conducted to compare the performance of uninfected and HIV-infected family- and institution-reared children in the younger and older groups on ToM demonstrated a significant effect for the younger children, $\chi^{2}(3, N=29)=7.58$, Fisher exact $p=.04$, again with family-reared uninfected children outperforming the other three groups of children, and no effect for the older children, $\chi^{2}(3, N=29)=3.62$, Fisher exact $p=.35$.

\section{Cognitive Development and Environmental Characteristics}

To compare the rearing environments of HIVinfected family- and institution-reared children, one-way ANOVAs on HOME subscales and HOME total scores were conducted (see Table 4; HOME scores were not available for the non-HIV-infected participants; see the Method section). To obtain an accurate picture of the magnitude of the differences between the two groups on the various HOME scales, independent of sample size, we also present effect sizes, as reflected by Cohen's $d$. According to Cohen (1988), $d=0.20$ can be interpreted as a small effect size, $d=0.50$ as medium, and $d=0.80$ as large. The rearing environment of the HIV-infected institution-reared children was scored significantly

Table 4

Mean Values, Standard Deviations, and Correlations With Cognitive Performance on SON-R Scores for HOME Scales of HIV-Infected Children as a Function of Rearing Environment

\begin{tabular}{|c|c|c|c|c|c|c|c|c|}
\hline \multirow[b]{2}{*}{ Scale } & \multicolumn{2}{|c|}{ Total $(N=29)$} & \multicolumn{2}{|c|}{$\begin{array}{c}\text { Family-reared } \\
\text { children }(N=16)\end{array}$} & \multicolumn{2}{|c|}{$\begin{array}{l}\text { Institution-reared } \\
\text { children }(N=13)\end{array}$} & \multirow[b]{2}{*}{$F$} & \multirow[b]{2}{*}{$d$} \\
\hline & $M(S D)$ & $r$ & $M(S D)$ & $r$ & $M(S D)$ & $r$ & & \\
\hline Learning Materials & $6.41(2.57)$ & .29 & $6.13 \quad(2.96)$ & .31 & $6.77(2.05)$ & .54 & 0.44 & -0.25 \\
\hline Language Stimulation & $5.69(1.39)$ & $.54^{* *}$ & $6.00 \quad(1.67)$ & $.50^{* *}$ & $5.31(0.86)$ & .52 & 1.83 & 0.52 \\
\hline Physical Environment & $4.79(1.61)$ & -.18 & $3.81 \quad(1.60)$ & .20 & $6.00(0.00)$ & .25 & $24.11^{* *}$ & -1.94 \\
\hline Responsivity & $5.93(1.71)$ & .12 & $6.00 \quad(1.75)$ & .02 & $5.85(1.73)$ & .24 & 0.06 & 0.07 \\
\hline Academic Stimulation & $4.10(1.18)$ & .13 & $4.19 \quad(1.38)$ & .08 & $4.00(0.91)$ & .19 & 0.18 & 0.16 \\
\hline Modeling & $5.14(1.27)$ & .23 & $5.44 \quad(1.46)$ & .10 & $4.77(0.93)$ & .25 & 2.05 & 0.55 \\
\hline Variety & $6.41(1.84)$ & -.02 & $5.63 \quad(2.09)$ & .24 & $7.38(0.77)$ & .23 & $8.23^{* *}$ & -1.11 \\
\hline Acceptance & $3.17(0.89)$ & $.42^{*}$ & $3.63 \quad(0.89)$ & .15 & $2.62(0.51)$ & .48 & $13.31^{* *}$ & 2.84 \\
\hline Total & $41.66(8.02)$ & .28 & $40.81(10.21)$ & .30 & $42.69(4.21)$ & $.66^{* *}$ & 0.39 & -0.24 \\
\hline
\end{tabular}

Note. SON-R = Snijders-Oomen Nonverbal Intelligence Test-Revised; HOME $=$ Home Observation for Measurement of the Environment.

${ }^{*} p<.05 .{ }^{* *} p<.01$. 
higher than the environment of HIV-infected family-reared children on the Physical Environment subscale, $F(1,27)=24.11, p<.01(d=-1.94)$, and the Variety subscale, $F(1,27)=8.23, p<.01$ $(d=-1.11)$, and significantly lower on the Acceptance subscale, $F(1,27)=13.31, p<.01(d=2.84)$. No difference was found on the HOME total score, $F(1,27)=0.39, p=.54(d=-0.24)$.

To examine how various aspects of the rearing environment as reflected by the HOME subscales were associated with the cognitive performance of HIV-infected children, we computed the correlations between the HOME subscales and SON-R scores (see Table 4). For the whole group of HIVinfected children higher SON-R scores were related to more Language Stimulation $(r=.54)$, and more Acceptance $(r=.42)$. For HIV-infected familyreared children higher SON-R scores were related to more Language Stimulation $(r=.50)$. For HIVinfected institution-reared children, higher SON-R scores were related to higher total HOME scores $(r=.66)$. We did not find any significant relations between the HOME subscales and current height, diurnal cortisol production, and ToM performance.

\section{Discussion}

Both HIV infection and institutional care are related to delayed physical growth and poor cognitive performance. The impact of the rearing environment on physical growth and cognitive performance on SON-R was, however, greater than the impact of HIV infection. Family care, even of compromised quality, was found to be more favorable for children's physical growth and cognitive development than institutional care. HIV-infected children reared in disadvantaged families showed better physical and cognitive development not only in comparison to HIV-infected children, but also compared to noninfected relatively healthy children reared in institutions providing good quality physical environments. In families as well as in institutions, better quality of the rearing environment was associated with higher levels of cognitive performance of HIV-infected children. We found elevated diurnal cortisol production in uninfected institution-reared children, and lower levels of diurnal cortisol production in their HIV-infected counterparts. Finally, uninfected children reared in families performed significantly better on the ToM task than all other groups.

The design of the current study provides a unique opportunity to examine how perinatal HIV infection and early rearing environment affect stress regulation, physical growth, and cognitive development of children in an ethnically homogeneous group. Moreover, to control for major differences in the duration and type of institutional care, we assessed children who were admitted to institutional care at 1 month after birth on average and who permanently resided in child-care institutions with about the same level of institutional privation.

\section{Physical Growth}

The association between HIV status and lower birth weight and physical growth delays has been well documented in previous studies (e.g., Bailey et al., 1999; European Collaborative Study, 2003), and was replicated in our sample. Archival data showed that delays in physical development of HIV-infected children were evident already at birth and persisted through the course of the child's development as compared to noninfected children raised in similar rearing environments. However, physical growth delays of HIV-infected children reared in families were less substantial in comparison to not only HIV-infected but also uninfected institution-reared children, who received adequate nutritional provision and health care, and whose physical environment was not significantly different from the environment of their family-reared counterparts as revealed by the HOME total score.

\section{Stress Regulation}

Our finding of an interaction effect between HIV status and type of care on total diurnal cortisol production indicates that the institutional environment, as a source of repeated daily intermittent stress, may cause an elevation of cortisol production for uninfected children, as also documented in other studies addressing stress regulation of children with institutional experience (e.g., Gunnar, Morison, Chisholm, \& Schuder, 2001). In the case of HIV-infected children, it may contribute to a weakened immune system functioning that allows HIV to have a greater inhibiting impact on cortisol production as compared to HIV-infected family-reared children. However, since family- and institutionreared children had similar CD4 T-lymphocyte counts (reflecting the level of immune control over the infection), an alternative and perhaps more plausible explanation is related to antiretroviral treatment that the majority of the HIV-infected institution-reared children and less than half of the family-reared children were receiving, which may 
also inhibit production of cortisol (e.g., Marik et al., 2002).

\section{Cognitive Performance on $S O N-R$}

The cognitive performance of the uninfected family-reared children was in the average range, whereas in the HIV-infected family-reared children it was in the borderline deficiency range, and in both uninfected and HIV-infected institution-reared children it fell in the range of mental deficiency (Tellegen et al., 1998). For institutionalized children, the impact of the infection on cognitive functioning appeared to be not very substantial. In fact, not all aspects of cognitive functioning may be equally affected by the presence of HIV. For example, along with normal performance of HIV-infected children on various measures of IQ, lower levels of performance have been found for executive functioning and processing speed (Koekkoek, De Sonneville, Wolfs, Licht, \& Geelen, 2007), visual-spatial and time orientation tests (Tardieu et al., 1995), and motor development (Blanchette et al., 2002). The SON-R test used in our study was not meant to detect impairments in executive functioning.

At the same time, a substantial discrepancy in cognitive performance between family-reared children with and without HIV was observed: It was more than 3 times larger than between institutionreared children with and without HIV. This discrepancy may be attributed to the difference in the rearing circumstances in the HIV-infected and uninfected families. Whereas uninfected children were from relatively normally functioning low-tomiddle class families, HIV-infected children were growing up in more problematic family environments. The relatively small difference in cognitive performance of institution-reared children may be explained by the fact that both uninfected and HIVinfected children were raised in mixed groups in the same institutions, and their rearing circumstances were nearly identical. Alternatively, it may reflect a general floor effect in non-neurologically impaired groups.

On average, the institution-reared children were more than 22 IQ points behind the family-reared children, and the gap between HIV-infected institution-reared children and their family-reared counterparts was more than 15 IQ points. Examination of the rearing environments of HIV-infected children living in families and institutions with the HOME inventory revealed no significant differences on the HOME total score between those groups. Interestingly, scores on the individual
HOME scales indicate that in comparison to the rearing environment of HIV-impacted families, child-care institutions were providing more toys, books, and games that facilitate learning; the physical environment of the institutions was safer, offered more space, and was perceptually more appealing. Finally, the care arrangements in the institutions provided more variety for the children. However, despite these benefits, HIV-infected institution-reared children showed greater cognitive delay than their family-reared counterparts. Further examination of the individual scales of the HOME inventory revealed that caregivers of the HIVinfected family-reared children were more accepting. Basically, institutional care was offering a better physical environment, whereas families secured more supportive child-caregiver interaction. Our findings suggest that the presence of a primary caregiver, and family care, even of compromised quality, promotes cognitive development of HIV-infected children above institutional care. Importantly, we found that correlations between cognitive performance and different aspects of the rearing environment reflected by the HOME scales were of considerable strength-even if they were not always statistically significant due to small subsample sizes. Also, the overall quality of care within institutions was associated with the cognitive performance of HIV-infected children; however, fairly adequate physical aspects of the rearing environment appeared to be insufficient to facilitate normative cognitive development.

\section{Theory of Mind}

More than half of the uninfected family-reared children passed the ToM task assessing the acquisition of false belief understanding, which was more than two times more than in the remaining three groups of children. This difference was especially evident among the younger children. This finding confirms that the average expectable environment facilitates earlier acquisition of ToM. However, although HIV-impacted families secured better child-caregiver interaction than in institutions, it was not sufficiently better to facilitate early ToM development, which requires from caregivers a certain level of sensitivity, fine tuning and mind-mindedness as well as the ability to focus on the child's thoughts and feelings (Fonagy, Gergely, \& Target, 2007). In the same vein, another study addressing the development of ToM in family- and institutionreared children demonstrated significantly better results for family-reared children from middle-SES 
families and failed to demonstrate statistically significant differences between children reared in low SES families and in institutions (Yagmurlu et al., 2005).

\section{Limitations and Future Directions}

The major limitation of the current study is its modest sample size that calls for replication of our findings in other countries and institutional settings. However, the power of the study was adequate $(>.80)$ and sufficient to find significant differences of the expected magnitude. The design of the study did not allow for random assignment of children to conditions. Because of the scarce information on perinatal development, we were only able to account for possible effects of birth weight as a proxy for perinatal insults. Besides, children in the four settings may have been systematically different in their genetic makeup, and further studies are needed to extend our understanding of how such genetic differences might contribute to the development of institution-reared children, making them less or more vulnerable to the negative effects of structural neglect (Rutter, 2006). Finally, the group of uninfected familyreared children was different from the other three groups in that these families most likely provided the average expectable environment. On the one hand, conclusions regarding the effects of HIV status on developmental outcomes should remain preliminary until direct comparison with a group of high-risk families without HIV-infected children is made. On the other hand, it does allow assessing differences in the effects of the average expectable environment and institutional care among uninfected children. It should also be noted that income differences between the two types of families were not associated with children's growth parameters, cortisol production, and cognitive development.

\section{Practical Implications}

Our study has important practical implications, especially concerning the development and implementation of intervention efforts in child-care institutions, which is the important strength and impact of this study. Our results indicate that it seems to be the quality of child-caregiver relationships and not so much the presence of HIV infection or the quality of the physical environment that contributed to the (delays in) growth and cognitive development of the children in our study. This finding points to the importance of comprehensive but focused intervention efforts in child-care institutions. Renovation of premises and equipping them with toys and learning materials, which has become a popular form of intervention in Eastern Europe, is certainly valuable, but our findings suggest that they may not be sufficient to decrease the gap between the institutional environment and the environment necessary for normative child development.

Of course, family-type of care is the best alternative for institution-reared children. Recent findings of the Bucharest Early Intervention Project (BEIP) in which children were randomly assigned to foster families or institutional care demonstrated that by the age of 4 , children in foster care were scoring almost 10 points higher on IQ tests than the children left in the orphanages, and those children who left the orphanages before 2 years of age saw an almost 15-point increase (Nelson et al., 2007). However, much time may pass before in Ukraine, with about 112,000 children under the age of 17 years reared in institutions (State Institute for Family and Youth Development, 2007), emerging alternative care and especially foster care for children with special needs and HIV will substitute institutional care. Unfortunately, HIV-related stigma and fears are still dominating among the general population. Some of the caregivers who participated in our study admitted that they had to conceal their involvement with HIV-infected children from their families. Not surprisingly, children with HIV remain the least preferred candidates for adoption or foster care. Therefore, intervention programs ameliorating the impact of institutionalization are of high importance for those children who are lacking the alternatives of growing up in family care. We believe that in such cases institutions offering good nutritional support and health care, especially important when adherence to the treatment regime is required, may serve at least as a temporary resort for the children. However, changing the structural neglect by enhancing the stability and the quality of the child-caregiver relationship should be a precondition and the major target of the intervention efforts (St. Petersburg-USA Orphanage Research Team, 2008).

Thus, our study fulfills an important pilot function, increasing our knowledge about the physical and cognitive development of an emerging specialneeds group of HIV-infected children reared in child-care institutions. Especially now, when the number of HIV-infected children in Ukraine and elsewhere in the world is growing, we hope that the examination of possible risk and protective factors 
affecting their development will contribute to a better understanding of their developmental processes, and to practical recommendations that ultimately lead to an improvement of their quality of life.

\section{References}

Azar, R., Zoccolillo, M., Paquette, D., Quiros, E., Baltzer, F., \& Tremblay, R. E. (2004). Cortisol levels and conduct disorder in adolescent mothers. Journal of the American Academy of Child and Adolescent Psychiatry, 43, 461-468.

Bailey, R. C., Kamenga, M. C., Nsuami, M. J., Nieburg, P., \& St. Louis, M. E. (1999). Growth of children according to maternal and child HIV, immunological and disease characteristics: A prospective cohort study in Kinshasa, Democratic Republic of Congo. International Journal of Epidemiology, 28, 532-540.

Bakermans-Kranenburg, M. J., van IJzendoorn, M. H., \& Juffer, F. (2008). Earlier is better: A meta-analysis of 70 years of intervention improving cognitive development in institutionalized children. Monographs of the Society for Research of Child Development, 73, 279-293.

Bakermans-Kranenburg, M. J., van IJzendoorn, M. H., Mesman, J., Alink, L. R. A., \& Juffer, F. (2008). Effects of an attachment-based intervention on daily cortisol moderated by DRD4: A randomized control trial on 1-3-year-olds screened for externalizing behavior. Development and Psychopathology, 20, 805-820.

Baron-Cohen, S. (1992). The theory of mind hypothesis of autism: History and prospects of the idea. The Psychologist, 5, 9-12.

Baron-Cohen, S., Leslie, A. M., \& Frith, U. (1985). Does the autistic child have a 'theory of mind? Cognition, 21, 37-46.

Blanchette, M., Smith, M. L., King, S., Fernandes-Penney, A., \& Read, S. (2002). Cognitive development in school age children with vertically transmitted HIV infection. Developmental Neuropsychology, 21, 223-241.

Bowlby, J. (1998). Attachment and loss: Vol. 2: Separation. London: Pimlico.

Bradley, R. H. (1985). Social-cognitive development and toys. Topics in Early Childhood Special Education, 5, 11-30.

Bradley, R. H., Whiteside, L., Caldwell, B. M., Casey, P. H., Kelleher, K., Pope, S., et al. (1993). Maternal IQ, the home environment, and child IQ in low birthweight premature children. International Journal of Behavioral Development, 16, 61-74.

Brown, L. K., Lourie, K. J., \& Pao, M. (2000). Children and adolescents living with HIV and AIDS: A review. Journal of Child Psychology and Psychiatry, 41, 81-96.

Caldwell, B. M., \& Bradley, R. H. (2003). Home observation for measurement of the environment. Little Rock: University of Arkansas at Little Rock.

Castle, J., Groothues, C., Bredenkamp, D., Becket, C., O'Connor, T., \& Rutter, M. et al. (1999). Effects of qualities of early institutional care on cognitive attainment. American Journal of Orthopsychiatry, 69, 424-437.
Cicchetti, D., Rogosch, F. A., Maughan, A., Toth, S. L., \& Bruce, J. (2003). False belief understanding in maltreated children. Development and Psychopathology, 15, 1067-1091.

Cicchetti, D., \& Valentino, K. (2006). An ecological transactional perspective on child maltreatment: Failure of the average expectable environment and its influence upon child development. In D. Cicchetti \& D. J. Cohen (Eds.), Developmental psychopathology risk, disorder, and adaptation (Vol. 3, 2nd ed., pp. 129-201). New York: Wiley.

Cohen, J. (1988). Statistical power analysis for the behavioral sciences. Hillsdale, NJ: Earlbaum.

Coscia, J. M., Christensen, B. K., Henry, R. R., Wallston, K., \& Radcliffe, J. (2001). Effects of home environment, socioeconomic status, and health status on cognitive functioning in children with HIV-1 infection. Journal of Pediatric Psychology, 26, 321-329.

Dean, A. G., Arner, T. G., Sunki, G. G., Friedman, R., Lantinga, M., \& Sangam, S. et al. (2002). Epi Info, a database and statistics program for public health professionals. Atlanta, GA: Centers for Disease Control and Prevention.

De Bellis, M.D. (2005). The psychobiology of neglect. Child Maltreatment, 10, 150-172.

De Martino, M., Tovo, P., Balducci, M., Galli, L., Gabiano, C., Rezza, G., et al. (2000). Reduction in mortality with availability of antiretroviral therapy for children with perinatal HIV-1 infection. JAMA, 284, 190-197.

Dobrova-Krol, N., van IJzendoorn, M., Bakermans-Kranenburg, M., Cyr, C., \& Juffer, F. (2008). Physical growth delays and stress dysregulation in stunted and nonstunted Ukrainian institution-reared children. Infant Behavior and Development, 31, 539-553.

Ellis, M., Shrestha, L., Shrestha, P. S., Manandhar, D. S., Bolam, A. J., \& de L Costello, A.M. (2001). Clinical predictors of outcome following mild and moderate neonatal encephalopathy in term newborns in Kathmandu, Nepal. Acta Paediatrica, 90, 316-322.

European Collaborative Study. (2003). Height, weight and growth in children born to mothers with HIV-1 infection in Europe. Pediatrics, 111, e52-e60.

Evans, G. W. (2006). Child development and the physical environment. Annual Review of Psychology, 57, 255-284.

Fishkin, P. E., Armstrong, F. D., Routh, D. K., Harris, L., Thompson, W., Miloslavich, K., et al. (2000). Brief report: Relationship between HIV infection and WPPSI$\mathrm{R}$ performance in preschool age children. Journal of Pediatric Psychology, 25, 347-351.

Fonagy, P., Gergely, G., \& Target, M. (2007). The parent-infant dyad and the construction of the subjective self. Journal of Child Psychology and Psychiatry, 48, 288-328.

Garfield, J. L., Peterson, C. C., \& Perry, T. (2001). Social cognition, language acquisition and the development of theory of mind. Mind and Language, 16, 494-541. 
Gottlieb, G., \& Blair, C. (2004). How early experience matters in intellectual development in the case of poverty. Prevention Science, 5, 245-252.

Gunnar, M. R. (2001). Effects of early deprivation. In C. A. Nelson \& M. Luciana (Eds.), Handbook of developmental cognitive neuroscience (pp. 617-629). Cambridge, MA: MIT Press.

Gunnar, M. R., Morison, S. J., Chisholm, K., \& Schuder, M. (2001). Salivary cortisol levels in children adopted from Romanian orphanages. Development and Psychopathology, 13, 611-628.

Gunnar, M. R., \& Vazquez, M. (2006). Stress neurobiology and developmental psychopathology. In D. Cicchetti \& D. Cohen (Eds.), Developmental psychopathology, developmental neuroscience (Vol. 2, 2nd ed., pp. 533-577). New York: Wiley.

Hakimi-Manesh, Y., Mojdchi, H., \& Tashakkori, A. (1984). Short communication: Effects of environmental enrichment on the mental and psychomotor development of orphanage children. Journal of Child Psychology and Psychiatry, 25, 643-650.

Hartmann, H. (1958). Ego psychology and the problem of adaptation. New York: International Universities Press.

Hughes, C., Adlam, A., Happe, F. G. E., Jackson, J., Taylor, A., \& Capsi, A. (2000). Good test-retest reliability for standard and advanced false-belief tasks across a wide range of abilities. Journal of Child Psychology and Psychiatry, 41, 483-490.

Hunt, J. M., Mohandessi, K., Ghodssi, M., \& Akiyama, M. (1976). The psychological development of orphanage reared infants: Interventions with outcomes. Genetic Psychology Monographs, 94, 177-226.

Jenkinson, J., Roberts, S., Dennehy, S., \& Tellegen, P. (1996). Validation of the Snijders-Oomen Nonverbal Intelligence Test-Revised 2.5-7 for Australian children with disabilities. Journal of Psychoeducational Assessment, 14, 276-286.

Johnson, R., Browne, K., \& Hamilton-Giachritsis, C. (2006). Young children in institutional care at risk of harm: A review. Trauma, Violence and Abuse, 7, 34-60.

Klunklin, P, \& Harrigan, R. C. (2002). Child-rearing practices of primary caregivers of HIV-infected children: An integrative review of the literature. Journal of Pediatric Nursing, 17, 289-296.

Koekkoek, S., De Sonneville, L. M., Wolfs, T. F., Licht, R., \& Geelen, S. P. (2007). Neurocognitive function profile in HIV-infected school-age children. European Journal of Paediatric Neurology, 12, 290-297.

Marik, P. E., Kiminyo, K., \& Zaloga, G.P. (2002). Adrenal insufficiency in critically ill HIV infected patients. Critical Care Medicine, 30, 1267-1273.

McMichael, A. J., \& Rowland-Jones, S. L. (2001). Cellular immune responses to HIV. Nature, 410, 980-987.

Miller, L. C. (2005). The handbook of international adoption medicine. A guide for physicians, parents, and providers. Oxford, UK: Oxford University Press.

Miller, L. C., Chan, W., Litvinova, A., Rubin, A., Tirella, L., \& Cermak, S. (2007). Medical diagnoses and growth of children residing in Russian orphanages. Acta Paediatrica, 96, 1765-1769.

Morison, S. J., Ames, E. W., \& Chisholm, K. (1995). The development of children adopted from Romanian orphanages. Merrill-Palmer Quarterly, 41, 411-430.

Nelson, C. (2007). A neurobiological perspective on early human deprivation. Child Development Perspectives, 1, 13-18.

Nelson, C., Zeanah, C. H., Fox, N. A., Marshall, P. J., Smyke, A. T., \& Guthrie, D. (2007). Cognitive recovery in socially deprived young children: The Bucharest Early Intervention Project. Science, 318, 1937-1940.

Nobel, K. G., McCandliss, B. D., \& Farah, M. J. (2007). Socioeconomic gradients predict individual differences on neurocognitive abilities. Developmental Science, 10, 464-480.

Nordstrom-Klee, B., Delaney-Black, V., Covington, C., Ager, J., \& Sokol, A. (2002). Growth from birth onwards of children prenatally exposed to drugs: A literature review. Neurotoxicology and Teratology, 24, 481488.

Pears, K. C., \& Fisher, P. (2005). Emotion understanding and theory of mind among maltreated children in foster care: Evidence of deficits. Development and Psychopathology, 17, 47-65.

Pruessner, J. C., Kirschbaum, C., Meinlschmid, G., \& Hellhammer, D.H. (2003). Two formulas for computation of the area under the curve represent measures of total hormone concentration versus time-dependent change. Psychoneuroendocrinology, 28, 916-931.

Rutter, M. (2006). Genes and behavior. Nature-nurture interplay explained. Oxford, UK: Blackwell.

Shankaran, S., Das, A., Bauer, C. R., Bada, H. S., Lester, B., Wright, L., et al. (2004). Association between patterns of maternal substance use and infant birth weight, length, and head circumference. Pediatrics, 114, e226-e234.

Skuse, D., Reilly, S., \& Wolke, D. (1994). Psychosocial adversity and growth during infancy. European Journal of Clinical Nutrition, 48, 113-130.

Smith, R., Malee, K., Leighty, R., Brouwers, P., Mellins, C., Hittelman, C., et al. (2006). Effects of perinatal HIV infection and associated risk factors on cognitive development among young children. Pediatrics, 117, 851-862.

Smyke, A. T., Koga, S.F., Johnson, D.E., Fox, N.A., Marshall, P.J., Nelson, C. A., et al. (2007). The caregiving context in institution reared and family reared infants and toddlers in Romania. Journal of Child Psychology and Psychiatry, 48, 210-218.

State Institute for Family and Youth Development (2007). National Report on Implementation of the Decisions of the Final Outcome Document of the United Nations General Assembly Special Session on Children (2002) and Action Plan "A World Fit for Children." Kiev: Ministry of Family, Youth, and Sport of Ukraine.

Steele, R. G., Nelson, T. D., \& Cole, B. P. (2007). The psychosocial adjustment of children and adolescents with HIV: Review from a socio-ecological perspective. 
Journal of Developmental and Behavioral Pediatrics, 28, 58-69.

St. Petersburg-USA Orphanage Research Team. (2008). The effects of early social-emotional and relationship experience on the development of young orphanage children. Monographs of the Society of Research in Child Development, 73 (Serial No. 291).

Tabachnik, B. G., \& Fidell, L. S. (2007). Using multivariate statistics (5th ed.). New York: Allyn \& Bacon.

Tardieu, M., Mayaux, M., Seibel, N., Funck-Bretano, I., Straub, E., Tegles, J., et al. (1995). Cognitive assessment of school-age children infected with maternally transmitted human immunodeficiency virus Type 1. Journal of Pediatrics, 126, 375-379.

Tarullo, A. R., Bruce, J., \& Gunnar, M. R. (2007). False belief and emotion understanding in post-institutionalized children. Social Development, 16, 57-78.

Tellegen, P., \& Laros, J. (1993). The construction and validation of a nonverbal test of intelligence: The revision of the Snijders-Oomen tests. European Journal of Psychological Assessment, 9, 147-157.

Tellegen, P. J., Winkel, M., Wijnberg-Williams, B. J., \& Laros, J. A. (1998). Snijders-Oomen Nonverbal Intelligence Test, SON-R 2.5-7, Manual and research report. Lisse, Netherlands: Swets \& Zeitlinger.

United Nations International Children's Emergency Fund. (2007). Children and AIDS: A stocktaking report. Retrieved February 15, 2008, from http://data. unaids.org/pub/Report/2007/20060116_stocktaking_ report.pdf

Van Handel, M., Swaab, H., De Vries, L. S., \& Jongmans, M. J. (2007). Long-term cognitive and behavioral conse- quences of neonatal encephalopathy following perinatal asphyxia: A review. European Journal of Pediatrics, 166, 645-654.

van IJzendoorn, M. (2008). Opvoeding over de grens. Gehechtheid, trauma en veerkracht. [Parenting across borders. Attachment, trauma and resilience]. Amsterdam: Boom Academic.

van IJzendoorn, M. H., Bakermans-Kranenburg, M. J., \& Juffer, F. (2007). Plasticity of growth in height, weight and head circumference: Meta-analytic evidence of massive catch-up of children's physical growth after adoption. Journal of Developmental and Behavioral Pediatrics, 28, 334-343.

van IJzendoorn, M. H., Luijk, M., \& Juffer, F. (2008). IQ of children growing up in children's homes: A meta-analysis on IQ delays in orphanages. Merrill-Palmer Quarterly, 54, 341-366.

Verbeek, A., \& Kroonenberg, P. (1985). A survey of algorithms for exact distributions of test statistics in $\mathrm{r} \times \mathrm{C}$ contingency tables with fixed margins. Computational Statistics and Data Analysis, 3, 159-185.

Wachsler-Felder, J. L., \& Golden, C. J. (2002). Neuropsychological consequences of HIV in children: A review of current literature. Clinical Psychology Review, 22, 441462.

Yagmurlu, B., Berument, S. K., \& Celimli, S. (2005). The role of institution and home contexts in theory of mind development. Journal of Applied Developmental Psychology, 26, 521-537.

Zhang, H., Gong, W., Sun, Y., \& Tian, X. (1997). SnijdersOomen Nonverbal Intelligence Test-Revision (SON-R) in China. Psychological Science China, 20, 97-103. 